\title{
ГЕОЭКОЛОГИЧЕСКАЯ ХАРАКТЕРИСТИКА И ОЦЕНКА ВЛИЯНИЯ СТРОИТЕЛЬСТВА МУРМАНСКОГО ТРАНСПОРТНОГО УЗЛА НА РОДНИК «ДОМАШНИЙ»
}

\author{
В. А. Глазова, И. А. Гапоненков, О.А. Федорова \\ Мурманский государственный технический университет, Россия \\ Центр лабораторного анализа и технических измерений по Мурманской области, Россия
}

Поступила в редакиию 22 апреля 2019 г.

\begin{abstract}
Аннотация: На основе данных исследования родников г. Мурманска и его пригорода, проведенного с марта 2014 года по март 2019 года, получена общая характеристика химического состава и качества родниковых вод. Рассматриваемый в статье водный объект располагается на территории Кольского района Мурманской области, в непосредственной близости от которого в настоящее время осуществляется строительство дорожной развязки Мурманского транспортного узла. В статье дана геоэкологическая оценка условий формирования родниковых вод п. Причальное Кольского района Мурманской области (родник «Домашний»). На основании пятилетних наблюдений составлена формула Курлова для данного родника. Оценка эколого-химического состояния родника производилась по следующим показателям: запах, цветность, водородный показатель (pH), хлориды, сульфаты, фосфат-ионы, нитрит-ионы, нитрат-ионы, перманганатная окисляемость (ПОК), общая щелочность, жесткость, общее железо, кальций, алюминий, ртуть, молибден, медь, стронций, никель. В результате исследования установлено, что на ионный состав родниковой воды главным образом влияют природные факторы - породы, слагающие водосборные бассейны, и климатические особенности региона. Повышение концентраций примесей в воде родника наблюдаются в весенние и осенние периоды и обусловлены инфильтрационной природой родниковых вод. Влияния буровзрывных работ на состав родниковой воды выявлено не было.
\end{abstract}

Ключевые слова: гидрохимический анализ, родниковая вода, геоэкологическая оценка, влияние строительства, Мурманский транспортный узел.

\section{Geoecological characteristics and assessment of the impact of the construction of the} Murmansk transport hub on the spring «Domashny»

\section{A. Glazova, I. A. Gaponenkov, O. A. Fedorova}

Abstract: Based on the data of the study of springs in Murmansk and its suburbs, conducted from March 2014 to March 2019, the characteristic of the chemical composition and quality of spring waters is obtained. The water object considered in the article is located on the territory of the Kola district of the Murmansk region, in the immediate vicinity of which the construction of a road junction of the Murmansk transport hub is currently taking place. Given geoecological estimation of conditions of formation of spring water in settlement Prichalnoein the Kola district of the Murmansk region. On the basis of longterm observations the formula Kurlova for this spring is made. The ecological and chemical state of the spring was assessed by the following indicators: odor, chromaticity, hydrogen index $(\mathrm{pH})$, chlorides, sulfates, phosphate ions, nitrite ions, nitrate ions, permanganate oxidability (POC), total alkalinity, hardness, total iron, calcium, aluminum, mercury, molybdenum, copper, strontium, nickel. The study found that the ionic composition of spring water is mainly influenced by natural factors - rocks that make up the catchment areas, and climatic features of the region. Increasing concentrations of pollutants in the spring water are observed in the spring and autumn periods and are due to the infiltration nature of spring waters. The influence of drilling and blasting operations on the composition of spring water was not revealed.

() Глазова В.А., Гапоненков И. А., Федорова О. А., 2019

Материал статьи доступен по лицензии

Creative Commons "Attribution" 4.0 
Key words: hydrochemical analysis, spring water, geoecological assessment, Murmansk transport hub.

\section{ВВЕДЕНИЕ}

В Российской Федерации исследования родниковых вод с целью определения их качественного состава проводились и проводятся в разных уголках страны: в Ингушетии [9], Башкортостане [3], Чечне [1], Удмуртии [11], в Перми [12], Ульяновске [7], Симферополе [6]. Но большинство исследований носит случайный характер (отбор проб проводится максимум в течение одного-двух лет), в связи с чем выводы о полной безопасности родниковой воды имеют отношение к тому временному отрезку, когда проводился анализ. Гипотетически можно предположить, что при отсутствии какой-либо техногенной/антропогенной деятельности в определенном радиусе от выхода подземных вод на поверхность качественный состав воды родника существенно не изменится.

В Мурманской области, богатой водными ресурсами, имеется множество родников, лишь незначительная часть которых используется людьми в питьевых целях. Сотрудники гидрогеологической группы ОАО «Центрально-Кольская экспедиция», химико-технологической лаборатории Кольского геологического информационно-лабораторного центра (г. Апатиты), бактериологической лаборатории ФГУЗ Центра гигиены и эпидемиологии по г. Мончегорску на протяжении 20 лет проводили исследования родниковой воды Кольского края, результатом этого огромного труда стал справочник В.Н. Ананьева «Родники Мурманской области» [2], в котором автор указывает на необходимость постоянного санитарного контроля качества воды в родниках.

Г.С. Михневич [8] отмечает, что «изменение качества подземных вод в результате загрязнения особенно заметно в промышленных зонах и в районах повышенной антропогенной нагрузки. В таких условиях весьма актуальна проблема своевременного выявления и охраны подземных вод от загрязнения».

Количественные исследования качественного состава питьевой воды в Российской Федерации, как правило, осуществляются на поверхностных водных объектах и в основном, концентрируются на определении содержания отдельных компонентов без учета всего комплекса физико-химических и биологических процессов, протекающих в этих водных объектах.

\section{ОБЪЕКТЫ И МЕТОДЫ ИССЛЕДОВАНИЯ}

Объектом исследования нами выбран родник «Домашний» № 42 Кольского района Мурманской области (название, приведенное в справочнике В. Н. Ананьева [2]).

Анализ воды родника в период с марта 2014 года по январь 2019 года осуществлялся по стандартным методикам.

Пробы воды исследовались на основные анионы в марте 2019 года в аккредитованной испытательной лаборатории «ЦЛАТИ по Мурманской области» хроматографическим методом по ПНД Ф 14.1:2:4.132-98, металлы - методом атомной абсорбции: ртуть - по М 01-55-2016, остальные - по ПНД Ф 14.1:2.253-09.

Качество воды оценивалось в соответствии с установленными санитарными правилами и нормами СанПиН 2.1.4.1175-02 «Гигиенические требования к качеству воды нецентрализованного водоснабжения. Санитарная охрана источников» [10].

С целью изучения геоэкологических условий формирования родниковых вод использовались метод изучения ранее опубликованных материалов и метод описательного обследования для получения данных о местонахождении, ландшафтных условиях и состоянии каптажа родника.

\section{РЕЗУЛЬТАТЫ ИССЛЕДОВАНИЯ И ИХ ОБСУЖДЕНИЕ}

Несмотря на свою принадлежность к районам Крайнего Севера России, климат района исследования арктически-умеренный, морской и, благодаря влиянию теплого Североатлантического течения, сравнительно с другими северными регионами, мягкий. Зимы умеренно холодные и длительные, при этом средняя температура января составляет $-10,4{ }^{\circ} \mathrm{C}$. Лето холодное и короткое, при этом средняя температура июля составляет $+12,9{ }^{\circ} \mathrm{C}$. Среднее годовое количество осадков - 490 мм. Самый сухой месяц - март (22 мм осадков). В августе количество осадков достигает своего пика (65 мм) [4].

Одним из самых популярных родников у населения является родник «Домашний» № 42, расположенный на выезде из поселка Причальное между 25 и 26 км автотрассы Мурманск-Верхнетуломский справа, в 27 м от дороги на склоне в непосредственной близости от жилого массива [2]. В радиусе полутора километров в западном и юго-западном направлениях расположены сельскохозяйственные угодья ГОУСП «Тулома», на которых выращивается зеленая масса для кормления скота.

Склон сложен песчано-галечно-валунными водноледниковыми образованиями. Поверхность склона поросла густым лиственным лесом очень 
Состав родниковой воды до и в период строительства

\begin{tabular}{|c|c|c|c|}
\hline Показатель & ПДК & $\begin{array}{c}\text { Май } 2014 \\
\text { (до начала } \\
\text { строительства) }\end{array}$ & $\begin{array}{c}\text { Май } 2018 \\
\text { (в период } \\
\text { строительства) }\end{array}$ \\
\hline Запах, баллы & не более 2-3 & 0 & 0 \\
\hline Цветность, градусы & не более 30 & 0 & 3 \\
\hline pH, единицы & в пределах 6-9 & 6,9 & 6,94 \\
\hline $\begin{array}{l}\text { Хлорид-ионы, } \\
\text { мг/дм }^{3}\end{array}$ & не более 350 & $<10$ & $<10$ \\
\hline $\begin{array}{l}\text { Фосфат-ионы, } \\
\text { мг/дм }{ }^{3}\end{array}$ & -* & 0,10 & 0,15 \\
\hline $\begin{array}{l}\text { Нитрит-ионы, } \\
\text { мг/дм }{ }^{3}\end{array}$ & - & $<0,02$ & 0,05 \\
\hline $\begin{array}{l}\text { Нитрат-ионы }\left(\mathrm{NO}_{3}{ }^{-}\right) \text {, } \\
\text { мг/дм }{ }^{3}\end{array}$ & не более 45 & 0,15 & 0,13 \\
\hline $\begin{array}{l}\text { Сульфат-ионы } \\
\left(\mathrm{SO}_{4}^{2-}\right), \text { мг/дм }\end{array}$ & не более 500 & - & 5,01 \\
\hline $\begin{array}{l}\text { Окисляемость } \\
\text { перманганатная, } \\
\text { мг/дм }{ }^{3}\end{array}$ & в пределах 5-7 & $<$ & 3,26 \\
\hline $\begin{array}{l}\text { Общая щелочность, } \\
\text { мг/дм }\end{array}$ & - & 1,2 & 1,2 \\
\hline $\begin{array}{l}\text { Жесткость общая, } \\
\text { Ж }\end{array}$ & в пределах 7-10 & - & 1,2 \\
\hline $\begin{array}{l}\text { Общее железо, } \\
\text { мг/дм }{ }^{3}\end{array}$ & - & - & 0,21 \\
\hline
\end{tabular}

Примечание. * знак «-» в таблице означает, что измерения не проводились.

влажным, замшелым. Каптаж родника выполнен в виде подпорной каменно-цементной стенки с выводом асбоцементной трубы для стока [2].

Более детальная характеристика родника приведена в справочнике В. Н. Ананьева [2]. С момента издания справочника в непосредственной близости от родника «Домашнего» началось строительство Мурманского транспортного узла, а именно железнодорожной линии от ст. Выходной до ст. Лавна с мостовым переходом через реку Тулома и ст. Мурмаши 2. В соответствии с полученной разрешительной документацией были выполнены буровзрывные работы. Общий объем перемещенного грунта составил $943000 \mathrm{~m}^{3}$ [5].

Тем не менее, общая геоэкологическая характеристика родника осталась прежней.

За все время наблюдений, с 2014 по 2019 год, пробы воды родника не имели запаха, а значения показателя «цветность» остались на уровне допустимых и варьируют от 4 до 23 градусов в зависимости от сезона года. В холодное время года цветность практически отсутствует, а в летние и осен- ние месяцы наблюдается ежегодное увеличение численных значений данного показателя.

Значения водородного показателя в исследуемых пробах воды находились в пределах установленных нормативов и изменялись в диапазоне от 6,52 до 7,26 единиц. Показатель «перманганатная окисляемость» в среднем составил 3,32 мг $\mathrm{O}_{2} /$ дм $^{3}$, что характеризует воду родника как незагрязненную.

Исследованные пробы воды на протяжении последних пяти лет определялись как воды с очень низкой и низкой минерализацией. В зависимости от сезона года данный показатель изменяется от 69 до 292 мг/дм³. Воду родника «Домашний» можно характеризовать как воду с очень низкой жесткостью (в среднем 1,25 мг-экв/дм³).

Содержание биогенных элементов в исследованных пробах воды в основном находилось у нижней границы предела определения, что свидетельствует об отсутствии источников техногенного загрязнения на площади водосбора.

Как показали последующие анализы, изменений качественного состава воды родника «Домаш- 
Геоэкологическая характеристика и оценка влияния строительства Мурманского транспортного узла на родник «Домаиний»

Таблица 2

Содержание тяжелых металлов в воде родника «Домашний» в марте 2019 года

\begin{tabular}{|l|c|c|c|c|c|c|}
\hline \multicolumn{1}{|c|}{ Металл } & $\mathrm{Al}$ & $\mathrm{Hg}$ & $\mathrm{Cu}$ & $\mathrm{Mo}$ & $\mathrm{Sr}$ & $\mathrm{Ni}$ \\
\hline $\begin{array}{l}\text { Концентрация, } \\
\text { мг/дм }\end{array}$ & $<0,02$ & $<0,00001$ & 0,0088 & $<0,001$ & 0,156 & 0,006 \\
\hline ПДК, мг/дм ${ }^{3}$ & 0,5 & 0,0005 & 1,0 & 0,25 & 7,0 & 0,1 \\
\hline
\end{tabular}

ний» в результате проведения буровзрывных работ не произошло (таблица 1).

Определенный интерес представляет наличие/ отсутствие тяжелых металлов в воде родника. Наши исследования показали, что содержание ионов ртути, молибдена, алюминия, стронция, никеля и меди находятся либо ниже предела определения, либо в количествах, не превышающих предельно допустимых концентраций (таблица 2).

На основании многолетних наблюдений авторами была составлена формула Курлова для родника «Домашний»:

$$
\text { pH 6,94 ж 0,71 M 0,04 } \frac{\mathrm{SO}_{4} 45 \mathrm{Cl}_{4} \mathrm{NO}_{3} 6 \mathrm{HCO}_{3} 4}{\mathrm{Ca} 100} \text {. }
$$

Согласно вышеуказанной формуле воду из родника можно характеризовать как близкую к нейтральной, очень мягкую, ультрапресную, гидрокарбонатную кальциевую.

\section{ЗАКЛЮЧЕНИЕ}

Проведение экологического мониторинга качества воды родника «Домашний» с марта 2014 по март 2019 года позволило дать ее объективную гидрохимическую оценку.

Установлено, что с момента издания справочника В. Н. Ананьева вода данного родника, несмотря на начало строительства транспортного узла, осталась гидрокарбонатно-кальциевой, ультрапресной, а ионный состав воды родника во многом зависит от природных особенностей рассматриваемой территории, в частности от подстилающих пород и климатических условий.

Качество воды родника «Домашний» в целом соответствует установленным нормативам для нецентрализованных источников питьевого водоснабжения. Однако, наблюдается повышение цветности и содержания общего железа в пробах воды в весенние и осенние сезоны, которые можно связать с природными факторами (паводки, интенсивное выпадение осадков). До апреля 2019 года не было выявлено влияния буровзрывных работ при строительстве Мурманского транспортного узла на качество воды в роднике «Домашний».

\section{СПИСОК ЛИТЕРАТУРЫ}

1. Аларханова 3. 3. Анализ родниковых вод ЧР / 3. 3. Аларханова, Р. С. Джамбулатов, С. С. Махаева // Известия Чеченского государственного педагогического института. - 2015. - Т. 2, № 3(11). - С. 38-42.

2. Ананьев В. Н. Родники Мурманской области : справочник / В. Н. Ананьев. - Мурманск : Книжное издательство, 2010. - 88 с.

3. Исследование родниковых вод Бирского района Республики Башкортостан / А. Р. Махмутов [и др.] // Бюллетень науки и практики. - 2016. - № 4(5). C. 62-69.

4. Климат : Кола. - URL: https://ru.climate-data.org/ азия/российская-федерация/мурманская-область/кола29799/ (дата обращения 09.02.2019).

5. Комплексное развитие Мурманского транспортного узла. - URL: http://ppp-transport.ru/ru/event/arhivsobytij/2016/kompleksnoe-razvitie-murman skogotransportnogo-uzla (дата обращения 09.02.2019).

6. Кузнецова Е. Ю. Оценка экологического состояния Даниловского ставка (г. Симферополь) / Е. Ю. Кузнецова, Д. А. Кучер // Человек-Природа-Общество: Теория и практика безопасности жизнедеятельности, экологии и валеологии. - 2015. - № 1. - С. 32-34.

7. Микробиологический мониторинг качества воды родников окрестностей города Ульяновска / Е. В. Рассадина [и др.] // Современные здоровьесберегающие технологии. - 2017. - № 4. - С. 407-417.

8. Михневич Г. С. Оценка защищенности подземных вод Калининградской области от загрязнения / Г. С. Михневич // Вестник Российского государственного университета им. Иммануила Канта. Сер. Естественные науки. - 2010. - № 1. - С. 93-101.

9. Санитарно-химический анализ родниковых вод на примере Республики Ингушетия / Л. Я. Ужахова [и др.] // Фундаментальные исследования. - 2012. - № 92. - С. 313-317.

10. СанПиН 2.1.4.1175-02. Гигиенические требования к качеству воды нецентрализованного водоснабжения. Санитарная охрана источников.

11. Химический состав водопроводной воды и некоторых природных источников г. Ижевска (февральмарт 2013 года) / М. М. Канунников [и др.] // Вестник Удмуртского университета. Сер. Физика и химия. 2013. - № 3. - С. 65-69.

12. Щукова И. В. Проблема качества питьевой воды (на примере г. Перми) / И. В. Щукова // Современные проблемы науки и образования. - 2014. - № 6. - С. 1664. 


\section{REFERENCES}

1. Alarkhanova Z.Z., Dzhambulatov R. S., Makhaeva S. S., Analiz rodnikovykh vod ChR [Analysis of spring waters of the Czech Republic], Izvestiya Chechenskogo gosudarstvennogo pedagogicheskogo instituta, 2015, Vol. 2, No. 3(11), pp. 38-42.

2. Anan'ev V. N., Rodniki Murmanskoy oblasti : spravochnik [Springs of the Murmansk region: a directory]. Murmansk, Knizhnoe izdatel'stvo, 2010, 88 p.

3. Makhmutov A. R. and etc, Issledovanie rodnikovykh vod Birskogo rayona Respubliki Bashkortostan [The study of spring waters of the Birsky district of the Republic of Bashkortostan]. Byulleten' nauki i praktiki, 2016, No. 4(5), pp. 62-69.

4. Klimat : Kola [Climate: Cola]. Available at: https:// ru.climate-data.org/aziya/rossiyskaya-federatsiya/murmanskaya-oblast'/kola-29799/ (accessed 09 February 2019).

5. Kompleksnoe razvitie Murmanskogo transportnogo uzla [Integrated development of the Murmansk transport hub]. Available at: http://ppp-transport.ru/ru/event/arhivsobytij/2016/kompleksnoe-razvitie-murmanskogo-transportnogo-uzla (accessed 09 February 2019).

6. Kuznetsova E. Yu., Kucher D. A., Otsenka ekologicheskogo sostoyaniya Danilovskogo stavka (g. Simferopol') [Assessment of the environmental status of Danilovsky bid (Simferopol)]. Chelovek-Priroda-Obshchestvo: Teoriya $i$ praktika bezopasnosti zhiznedeyatel'nosti, ekologii i valeologii, 2015, No. 1, pp. 32-34.

7. Rassadina E. V. and etc., Mikrobiologicheskiy monitoring kachestva vody rodnikov okrestnostey goroda

Глазова Валерия Андреевна

аспирант кафедры техносферной безопасности Мурманского государственного технического университета, г. Мурманск, E-mail: glazova.valerya@ yandex.ru

Гапоненков Иван Андреевич

старший преподаватель, научный сотрудник кафедры техносферной безопасности Мурманского государственного технического университета, г. Мурманск, E-mail:gaponenkovia@mstu.edu.ru

Федорова Ольга Анатольевна

кандидат технических наук, главный химик «Центра лабораторного анализа и технических измерений по Мурманской области», г. Мурманск, E-mail: olga_fiodorova@mail.ru
Ul'yanovska [Microbiological monitoring of water quality in the springs of the surroundings of the city of Ulyanovsk]. Sovremennye zdorov'esberegayushchie tekhnologii, 2017, No. 4, pp. 407-417.

8. Mikhnevich G. S., Otsenka zashchishchennosti podzemnykh vod Kaliningradskoy oblasti ot zagryazneniya [Assessment of the protection of groundwater in the Kaliningrad region from pollution]. Vestnik Rossiyskogo gosudarstvennogo universiteta im. Immanuila Kanta. Ser. Estestvennye nauki, 2010, No. 1, pp. 93-101.

9. Uzhakhova L. Ya. and etc., Sanitarno-khimicheskiy analiz rodnikovykh vod na primere Respubliki Ingushetiya [Sanitary-chemical analysis of spring waters by the example of the Republic of Ingushetia]. Fundamental'nye issledovaniya, 2012, No. 9-2, pp. 313-317.

10. SanPiN 2.1.4.1175-02. Gigienicheskie trebovaniya k kachestvu vody netsentralizovannogo vodosnabzheniya. Sanitarnaya okhrana istochnikov [SanPiN 2.1.4.117502. Hygienic requirements for water quality of non-centralized water supply. Sanitary protection of sources].

11. Kanunnikov M. M. and etc., Khimicheskiy sostav vodoprovodnoy vody i nekotorykh prirodnykh istochnikov g. Izhevska (fevral'-mart 2013 goda) [The chemical composition of tap water and some natural sources in Izhevsk (February-March 2013)]. Vestnik Udmurtskogo universiteta. Ser. Fizika i khimiya, 2013, No. 3, pp. 65-69.

12. Shchukova I. V., Problema kachestva pit'evoy vody (na primere g. Permi) [The problem of drinking water quality (for example, Perm)]. Sovremennye problemy nauki i obrazovaniya, 2014, No. 6, pp. 1664.

Glazova Valeriya Andreevna

Postgraduate student of the Department of technosphere safety of Murmansk State Technical University, Murmansk, E-mail: glazova.valerya@yandex.ru

Gaponenkov Ivan Andreevich

Senior lecturer, Researcherof the Department of technosphere safety of Murmansk State Technical University, Murmansk, E-mail: gaponenkovia@ mstu.edu.ru

Fyodorova Ol'ga Anatol'evna

Candidate of Technical Sciences, Chief chemist of the Centre for laboratory analysis and technical measurements in the Murmansk region, E-mail: olga fiodorova@mail.ru 